\title{
Responding to the Challenges with Implementing a Community-Based Potable Water System Project in a Rural Honduran Community
}

\author{
Xiaoyuan Jin \\ School of Public Health, University of California Irvine, CA, American \\ xiaoyuaj@uci.edu
}

\begin{abstract}
This paper talks about the water-associated problems that occur in San Gabriel, Honduras, and claims a few present coping methods. It is necessary to solve the water problem in Honduras as soon as possible to get rid of a series of severe health problems, including diarrhea outbreak and parasitism. Coping methods include inviting Engineers, Ltd. and give accesses to an organization called Potable Water for All. Moreover, the paper claims the emerging difficulties that have to be solved during the process of solving the water problems, such as lacking funds. The paper provides some recommendations and ongoing work of the Honduras water problems. It also presents a successful case of Kenya that can be used as the reference in the field of solving the water-associated problems.
\end{abstract}

Keywords: Water problems, Community- Based Potable Water System Project, Rural Honduran, Community.

\section{Introduction to the Problem}

The health case study delves into the challenges being faced in trying to implement a community-based potable water system project in rural Honduras. The problem exists because most of these households rarely have water with very few of them boasting of piped water. The majority of the time is spent in sourcing for water, an exercise that makes the precious commodity a health hazard due to unhygienic conditions and practices (Trevett, Carter \& Tyrell, 2004). The available yet contaminated water helps to spread parasitism and diarrhoea, contributing to the death of countless children.

In the rural Honduran community of San Gabriel, $90 \%$ of the people ferrying water are women. In addition, $60 \%$ of the homesteads use wells as their source of water while $20 \%$ of the households use a neighbor's well; and only $15 \%$ of the households able to use tap water with a further $5 \%$ using their neighbor's tap water.

\section{Present Situation Analysis}

The decision that the entire community of San Gabriel ought to make rests with their communal group, ADC. They are open to two options. One is with the Engineers, Ltd. who are interested in supplying water from central points so that it can be accessed by as many people as possible. From the access point, the rural residents would have to transport the water to their households. On the other hand, the PWFA proposed one single project for potable water to be distributed to all households (Hunting Gleason, 2011).

The public health organization of designing the water distribution system is the Potable Water For All (PWFA). The strength of this team is that improving the water supply and key hygiene behaviors to provide benefits to the community, and it gave five promoters from the community to make the hygiene be better. The Engineers, Ltd. Option seems attractive because it provides an instant solution to the acute water shortage facing the residents, unlike the PWFA project that has uncertainties in funding and timeline. This is because funding for the Engineers, Ltd. is available and the project has the commissioner's backing alongside half of the San Gabriel community. On the downside, the Engineers, Ltd. Option will be municipal-controlled and not directly linked to homes. The PWFA will deliver hygienic water straight to homesteads and all the administrative and ownership matters will rest 
with the community. It may take longer to complete, but the community members can be assured of subsidized costs.

Various stakeholders in the potable water project have divergent goals. The San Gabriel community, through the $\mathrm{ADC}$, is interested in owning and distributing the hygienic water equitably. There is the volunteer group PWFA that is focused on putting up a sustainable potable water project that serves households; while ASAR, an NGO in Honduras, is involved in protecting rural communities in the partnerships they establish with government agencies and promoting the rights of communities where the potable water system projects are ongoing. There is also the municipal administration that is keen on controlling the project and charging fees with the help of their constructors, Engineers, Ltd. whose main goal is to secure additional job contracts.

\section{Challenges and Issue to Consider}

There are different causes that can be attributed to the challenges faced in implementing the potable water project. The first one is the different objectives of the stakeholders involved. There are those who want to control and charge fees while others aim for equitable distribution in each household. There are also political issues to consider as the two separate factions have different sands on these projects. Additionally, It is also a challenge to implement the proposed project by volunteers when there is inadequate funding that prolongs the project's timeline and worsens the already biting water shortage. It has been a difficult journey for the volunteers as they make do without water for basic chores such as washing clothes. Volunteers have also encountered language and cultural barriers during the initial phase of the project. For instance, volunteers have difficulty in explaining to the rural residents how and why they cannot have water due to the recession as the majority of them cannot link the relationship between the two factors. Poor communication and understanding of new program between volunteers and residents further delay the progress for the community.

The problems that arise as a result of the lack of hygienic water include a diarrhea outbreak together with parasitism (Montgomery \& Elimelech, 2007). Diarrhoea severely affects children due to dehydration and a rapid loss of body fluids, causing high death rates. To combat parasitism, San Gabriel rural residents are forced to boil water for their children to drink. However, boiling water has increased wood fuel consumption and the disappearance of bushes. Grey water and stand water are also a common site in the Honduras rural area, with few households taking it upon themselves to clear these water pools. The water shortage has also contributed to the frequent outbreaks of dengue fever, a recurrence that leads many residents to seek medical treatment. As a result, rural Hondurans spend a lot of their hard earned income on medical bills, especially for their children.

\section{Analysis of Theoretical Perspectives}

Theoretical perspectives are the assumptions that were may make from the society based on answers to some underlying questions. There are three essential theoretical perspectives through which the given health case can be analyzed. The functionalist approach would view hygienic water that is equitably distributed in every homestead as a good thing for the rural community. The project would be community owned, with the members expected to comply with the decision making organ of the community (Harvey Reed, 2007). Under the conflict theoretical approach, social inequality is evident where a majority of the households obtain water from the well, while only a few can afford piped water to their homes. In addition, there are politicians and constructors out to profit on the water problem. In the symbolic interactionism theory, water shortage and unhygienic water are the makings of the community. Objective reality negates their existence until the community at large accepts that there is a problem of hygienic water. It calls for stakeholders to try and find a solution through their expertise and knowledge.

There are two alternatives from which the San Gabriel community members of rural Honduras can select to alleviate their water challenges. One is to accept the commissioner's project to be constructed by Engineers, Ltd., while the other one is to wait for the completion of the PWFA potable water project. 
The ideal solution, in this case, would be to wait for the PWFA project to be done in the second phase. This is because all stakeholders in this project want the community to benefit and in the end, the project ownership will go to the community. In this way, the members will be exempt from paying or be charged lower fees. "Further evaluation of this option as the best solution shows that there will be an abundant supply of piped and hygienic water for each home. Hygienic water will go a long way in solving a myriad of hygiene related illnesses within the San Gabriel community".

\section{Recommendations}

The suggested solution has been arrived at after carefully considering the following recommendations. First of all, the potable water project will be owned by the community and not the municipality once implemented. This will help the community to avoid the extra cost of having to pay a fee for getting water. It also means that the administrative and operational decisions of the water project will be in the hands of a decision making organ appointed by the community members (Whittington, et al., 2008). In addition, the volunteers in this project have pledged to train and build capacity among the members.

The second recommendation is derived from the delivery of hygienic water in each household in San Gabriel. As stated earlier, hygienic water will reduce the rate of infections and illness, especially among the vulnerable child population. Families will also be able to save the cash used in footing hospital bills. Fetching water straight from the tap within the home compound will save many families, and women to be specific, the long journeys to and from different water access points within the rural villages.

The third reason for recommending this solution is because it has the ability to nullify all the other options that appear to be self-serving and focus on the well-being of and focus on the well-being of the entire community. By not solely depending on the proposal that requires residents to carry water from potable water access points to their homes, fewer residents would be affected by the extortion of municipal officials and contractors. Ownership would not fall completely under the municipality's control. Not only that, the potential for thr health hazards through hazards through contaminated water would be reduced.

\section{Developing an Action Plan}

The specific activity required to attain the solution to the potable water challenge is the release of funds by Institution International, the financial stakeholders of the PWFA project. The financier has already funded the first phase of the project, only remaining with the eagerly awaited phase 2 .

Once these funds have been released, the volunteers spearheading this project will be responsible for completing the second phase. This will be a mammoth task because it means connecting all the households in San Gabriel with a supply of hygienic water. They will closely coordinate with the community association, ADC.

It is hard to specify the exact timeline within which the second part of the PFWA project will be completed because the Institution International is faced with challenges in sourcing for funds in an economic recession. However, the partial release of this money will help facilitate the completion of the project.

\section{Conclusion}

As a parting shot, I perceive the challenges presented in the public health Honduran case are practical in numerous rural setups around the world. It is a thought-provoking situation considering all the stakeholders involved, especially the community, which remains the key stakeholder. The high illiteracy levels in this rural population play a part in hindering the implementation of the potable water project in San Gabriel. Along with the language barrier and the confusing technical details of the project, the result is one intertwined challenge in implementing the project. However, these hindrances 
are partially eliminated with the recommended solution of a community owned and controlled potable water project that would ascertain the equitable distribution of hygienic water to every homestead within the San Gabriel canton.

Perhaps the best scenario for comparative purposes is the rural Kenyan situation. The study looks at a rural Kenyan situation where diarrhoea and other related ailments had become widespread as a result of poor sanitation and unhygienic practices. This necessitated the implementation of a hygienic water project with a view of making clean water accessible to as many Western province homes in rural Kenya (Makutsa, et al., 2001). This case is similar to the one inHonduras in that both were faced by numerous challenges from both ends of the community and participating stakeholders. The two cases are also similar in that they were kick-started and implemented by foreign volunteers in close cooperation with local NGOs. Illiteracy and ignorance cut across both cases, with the Kenyan rural community being adversely affected by harsh economic conditions and the lack of income generating avenues. In both instances, children suffer the most casualties from diarrhoea and its dehydrating effects. With numerous similarities between the two cases, the success found in the Kenyan case means that similar methods can be applied to the Honduras case with likely optimal outcomes.

\section{References}

[1]. Makutsa, P., Nzaku, K., Ogutu, P., Barasa, P., Ombeki, S., Mwaki, A., \& Quick, R. E. (2001). Challenges in implementing a point-of-use water quality intervention in rural Kenya. American Journal of Public Health, 91(10), 1571-1573.

[2]. Whittington, D., Davis, J., Prokopy, L., Komives, K., Thorsten, R., Lukacs, H., ... \& Wakeman, W. (2008). How well is the demand-driven, community management model for rural water supply systems doing?. Brooks World Poverty Institute Working Paper, (22).

[3]. Harvey, P. A., \& Reed, R. A. (2007). Community-managed water supplies in Africa: sustainable or dispensable?. Community Development Journal, 42(3), 365-378.

[4]. Trevett, A. F., Carter, R. C., \& Tyrrel, S. F. (2004). Water quality deterioration: a study of household drinking water quality in rural Honduras. International journal of environmental health research, 14(4), 273-283.

[5]. Montgomery, M. A., \& Elimelech, M. (2007). Water and sanitation in developing countries: including health in the equation. Environmental Science \& Technology, 41(1), 17-24.

[6]. Younos, T. \& Grady, C. A. (2014). Potable Water: Emerging Global Problems and Solutions. Springer.

[7]. Hunting, K. \& Gleason, B.L. (2011). Essential Case Studies in Public Health. Jones Bartlett Publishers. 